International Review of Research in Open and Distributed Learning Volume 22, Number 1

February - 2021

\title{
Are Highly Motivated Learners More Likely to Complete a Computer Programming MOOC?
}

Piret Luik and Marina Lepp

Institute of Computer Science, University of Tartu, Estonia

\begin{abstract}
Computer programming MOOCs attract people who have different motivations. Previous studies have hypothesized that the motivation declared before starting the course can be an important predictor of distinctive dropout rates. The aim of this study was to outline the main motivation clusters of participants in a computer programming MOOC, and to compare how these clusters differed in terms of intention to complete and actual completion rate. The sample consisted of 1,181 respondents to the pre-course questionnaire in the Introduction to Programming MOOC. A validated motivation scale, based on expectancy-value theory and k-means cluster analysis, was used to form the groups. The four identified clusters were named as Opportunity motivated (27.7\%), Over-motivated (28.6\%), Success motivated (19.6\%) and Interest motivated (24.0\%). Comparison tests and chi-square test were used to describe the differences among the clusters. There were statistically significant differences among clusters in selfevaluated probability of completion. Also, significant differences emerged among three clusters in terms of percentages of respondents who completed the MOOC. Interestingly, the completion rate was the lowest in the Over-motivated cluster. A statistically significant higher ratio of completers to non-completers was found in the Opportunity motivated, Success motivated, and Interest motivated clusters. Our findings can be useful for MOOC instructors, as a better vision of participants' motivational profiles at the beginning of the MOOC might help to inform the MOOC design to better support different needs, potentially resulting in lower dropout rates.
\end{abstract}

Keywords: MOOC, motivation, programming, clusters, completion 


\section{Introduction}

The interest in learning programming and computer science has been growing in recent years; nowadays society needs more and more people with programming skills. Massive open online courses (MOOCs) are a possible way to meet this demand and educate a large number of people. Despite their enormous popularity, MOOCs still have an extensive problem with dropout. One variable related to dropout is the motivation to start the course (Reparaz et al., 2020). Motivation to start the MOOC is different from motivation in traditional courses and is more diverse: some participants merely want to use the materials, others learners are highly motivated and follow every aspect of the course, while some simply enjoy interacting with other MOOC learners (Daza et al., 2013). It is important to understand how to make a MOOC work for as many of its diverse participants as possible (Grover et al., 2013).

Existing research on MOOCs has focused on classification of MOOC learners based on their behavior during the course (Feklistova et al., 2019; Kahan et al., 2017; Kizilcec et al., 2013; Tseng et al., 2016). However, different motivational goals may predict different behavioral patterns for MOOC learners and dropouts (Kizilcec \& Schneider, 2015), and MOOC completers can be characterized according to their motivation to learn (Barak et al., 2016). Lately, it has been shown that the classification of MOOC participants according to their motivations and intentions at the beginning of the MOOC can help to identify in advance the benefits and potential obstacles that one can find throughout a MOOC (Maya-Jariego et al., 2019). Therefore, this research aimed to outline the main motivation clusters of participants in a computer programming MOOC and compare the differences in completion rates between these clusters.

\section{Literature Review}

\section{Motivation}

Motivation can be defined as an internal state or condition that activates behavior and gives it direction (Huitt, 2011). Motivation can be affected by several factors, such as self-efficacy and competence beliefs, control beliefs, interest, value beliefs, and achievement goals (Pintrich, 2003). Motivation to learn is one type of motivation that can be conceptualized as the degree to which students invest attention and effort in various learning activities (Brophy, 2013). Motivation plays a key role in learning and academic performance (Green et al., 2012) and has an important effect on student achievement (Orhan Özen, 2017). In general, explanations relating to the sources of motivation can be categorized into two main categories: intrinsic (internal to the person) and extrinsic (outside the person; Deci et al., 2001). Studies on why people choose a teaching career have also added altruistic motivation, namely desire to improve the well-being of others (e.g., Anthony \& Ord, 2008; Brookhart \& Freeman, 1992; Tomšik, 2016).

Several theories of motivation are relevant to the learning domain (Brophy, 2013). Expectancy-value theory explains how motivation influences students' choice of achievement tasks, persistence on those tasks, and performance on them (Wigfield \& Eccles, 2000). This theory states that individuals' choice, persistence, and performance can be explained by their beliefs about how well they will do on the activity (i.e., expectancies for success) and the extent to which they value the activity or task (i.e., values; Wigfield \& Eccles, 2000). Expectancies and values are influenced by ability beliefs, the perceived difficulty of different 
tasks, and individual goals (Eccles \& Wigfield, 2002). Expectancies and values have a direct influence on achievement choices, performance, effort, and persistence (Wigfield \& Eccles, 2000). Different components of achievement values have been defined: (a) attainment value or importance of doing well, (b) intrinsic value or enjoyment from doing the task, (c) utility value or usefulness of the task, and (d) perceived cost to finish the task (Wigfield et al., 2020).

\section{Motivation in MOOCs}

Studying motivation in MOOCs, it is important to understand the value and worth of the MOOC for the participant (Macdonald \& Ahern, 2015). A wide range of motivations for using MOOCs has been described (Kizilcec \& Schneider, 2015; Luik et al., 2019; Milligan \& Littlejohn, 2017; Zheng et al., 2015). It has been found that the learners who enroll in MOOCs tend to have different motivations than learners in traditional courses (Watted \& Barak, 2018). Learners in MOOCs may not be focused on gaining a certificate of completion (Kizilcec et al., 2013) as course completion and certification is merely one of many potential outcomes of MOOC participation (Zheng et al., 2015). Learners can choose only parts of a MOOC according to their goals and interests (Kizilcec \& Schneider, 2015; Wang \& Baker, 2015; White et al., 2015).

Several studies have attempted to identify and describe the major motives in MOOCs and have proposed different lists. Zheng et al. (2015) named four types of MOOC learner motivation: (a) fulfilling current needs, (b) satisfying curiosity, (c) preparing for the future, and (d) connecting with people. Watted and Barak (2018) grouped participants' motivating factors into three themes-career benefits, personal benefits, and educational benefits-and found that the general interest category, under the personal benefit theme, and professional competence, under career benefits, were the major motivating factors. General interest in the topic, desire for growth and enrichment, and an expectation to have fun and be challenged were the major motivating forces reported by Kizilcec and Schneider (2015). Milligan and Littlejohn (2017) identified nine types of motivation for participating, with four primary motives: (a) the opportunity to learn about the topic, (b) general interest in the topic, (c) the relevance of the course topic to current role challenges, and (d) its relevance to future career intention. White et al. (2015) identified seven types of reasons for choosing a MOOC, including the following three most marked reasons: (a) MOOCs are free and open, (b) knowledge update, and (c) interest in topic. Luik et al. (2019) composed a scale for measuring motivation with seven factors, wherein the highest-rated motivational factors were interest in and expectations for the course, personal suitability of distance learning, and suitability for family and work.

The diversity of motivations can help predict persistence in a MOOC. Luik et al. (2018) found that the factors (a) interest and expectancies for course, (b) personal suitability of distance learning, (c) usefulness related to certification, and (d) social influence were rated higher by completers than by non-completers. Chaw and Tang (2019) showed that positive motivation (which consists of three elements: believing and having confidence in one's ability to perform well; valuing learning for its usefulness, importance, and relevance; learning to solve problems and develop skills) led to positive engagement, which promotes an increased tendency to complete MOOCs. Evans et al. (2016) claimed that participants who were motivated by their curiosity about online courses or by professional reasons tended to not persist. Wang and Baker (2015) showed that completers were more interested in the course content, whereas non-completers tended to be more interested in MOOCs as a type of learning experience. On the other hand, Douglas et al. (2020) argued that the scores of the Expectancy-Value-Cost motivation scale had only limited predictive power on 
performance, and Breslow et al. (2013) even stated that there were no correlations between motivation for enrollment and success in the course.

\section{Classifying MOOC Participants Based on Motivation and MOOC Completion}

A few studies have tried to classify MOOC participants according to their motivation and to look at specific completion data of the identified groups of participants. The methods used have included quantitative approaches, such as cluster analysis (Maya-Jariego et al., 2019) or data mining with clustering techniques (Gallén \& Caro, 2017), as well as qualitative techniques, such as inductive content analysis (Barak et al., 2016).

Based on content analysis of e-mail messages and forum posts, Barak et al. (2016) identified five types of MOOC completers according to their learning motivation. Networkers wish to meet people with similar interests. Problem-solvers seek to find a solution for a real problem from their work. Benefactors learn for the benefit of others and want to contribute to society. 'Innovation-seekers desire to stay constantly updated and informed. Complementary-learners are students who take the MOOC to broaden and deepen their curriculum.

Gallén and Caro (2017) used clustering techniques in order to better understand the external regulation and motivations of MOOC participants. They identified three motivational profiles they labeled as convinced, cautious, and irrelevant. Convinced participants did not consider the course a waste of time, wanted to do it, and would not prefer doing other things. Also, they did not lose face in front of others, did not consider that others thought badly of them, and did not get in a lot of trouble. Irrelevant participants felt a little guilty for not doing the course, a little ashamed of themselves, and thought that people might think badly about them. Cautious participants did not cluster items with high prevalence and their answers on a seven-point Likert-type scale were mostly of the applies somewhat to me variety. Their highest-rated item was somewhat preferring to do other things.

Maya-Jariego et al. (2019) classified participants based on motivation and learning intention. Three profiles of involvement in the course were identified: low interest, self-referential, and high commitment. All three profiles demonstrated significant differences in self-reported learning experiences at the end of the course. It was hypothesized that a significant predictor of differential dropout rates can be the motivation stated at the beginning of the course.

\section{Research Aim and Questions}

Maya-Jariego et al. (2019) used motivation and intent to complete MOOC as a diagnosis of drop-out. This study went further. We aimed to outline the main motivation clusters of participants in a computer programming MOOC, and to compare how these clusters differed in intention to complete and in completion rate. The study was based on the following research questions:

1. What kind of learner subgroups (clusters) can be identified based on motivation?

2. How do these clusters differ in intention to complete and in completion rates? 


\section{Methodology}

The Estonian-language computer programming MOOC named Introduction to Programming (in Estonian Programmeerimise alused) lasted for eight weeks, with an expected total workload of 78 hours. The course was designed for learners with little or no programming experience. The MOOC gave an overview of some programming techniques and taught the basics of algorithmic thinking. So far, this MOOC has been organized five times since the winter of 2016 and the completion rate has been over 50\% (Lepp et al., 2017).

\section{Sample and Data Collection}

The sample consisted of 1,181 respondents (571 male and 610 female) who enrolled in the Estonianlanguage MOOC Introduction to Programming organized by University of Tartu in the fall of 2018. Participants completed a pre-course questionnaire. Answering the questionnaire was voluntary and was not a prerequisite for passing the MOOC. The youngest participant was 10 years of age and the oldest was 70 ; the mean age of the participants was 32.4 years $(S D=10.82)$. Most of the participants had bachelor's (28.4\%) or master's (29.8\%) degrees. Of the participants, $64.2 \%$ were working and $25.9 \%$ were students. More than half of the participants (53.7\%) had not learned programming before and $21.6 \%$ had learned it only by themselves. Of those who filled in the pre-course questionnaire, 700 (59.3\%) went on to complete the MOOC.

As in several previous studies (e.g., Kizilcec \& Schneider, 2015; Zheng et al., 2015) this research used a quantitative approach to study motivation. Motivation was measured with a Factors Influencing Enrolment in MOOC (FIEM) scale based on expectancy-value theory (Eccles \& Wigfield, 2002). According to the results from confirmatory factor analysis, the scale consisted of 28 items, divided by 7 factors describing internal, external, and altruistic motivation; suitability of online learning; and social influence (Luik et al., 2019). This scale was chosen because it was based on motivational theory and covered different areas of motivation. A description of the scale with sample items is presented in Table 1.

The prefacing statement to all motivational items was "What did motivate you to enroll in the MOOC?", and all motivational items were presented on a 7-point Likert scale ranging from 1 (totally disagree) to 7 (totally agree). 


\section{Table 1}

Description of the Questionnaire Instrument

\begin{tabular}{|c|c|c|c|}
\hline Factor & Number of items & Examples & Cronbach's alpha \\
\hline $\begin{array}{l}\text { Interest in and } \\
\text { expectations of the } \\
\text { course }\end{array}$ & 8 & $\begin{array}{l}\text { I get more knowledge from this course } \\
\text { I can participate in a course with } \\
\text { excellent instructors } \\
\text { I am interested in that topic }\end{array}$ & .812 \\
\hline $\begin{array}{l}\text { Personal suitability of } \\
\text { distance learning }\end{array}$ & 4 & $\begin{array}{l}\text { I can choose the time, when I study } \\
\text { Learning, where I do not actually have } \\
\text { to meet other people, suits me }\end{array}$ & .799 \\
\hline $\begin{array}{l}\text { Suitability for family and } \\
\text { work }\end{array}$ & 2 & $\begin{array}{l}\text { I can combine learning with work } \\
\text { I can combine learning with family life }\end{array}$ & .762 \\
\hline $\begin{array}{l}\text { Importance and } \\
\text { perceived ability }\end{array}$ & 6 & $\begin{array}{l}\text { I need that knowledge in real life } \\
\text { I know that I do well in this topic }\end{array}$ & .814 \\
\hline $\begin{array}{l}\text { Usefulness related to } \\
\text { certification }\end{array}$ & 4 & $\begin{array}{l}\text { I can get a certificate from the } \\
\text { university } \\
\text { I can show it to the employer as good } \\
\text { professional development }\end{array}$ & .733 \\
\hline Social influence & 2 & $\begin{array}{l}\text { My friends think that I would be } \\
\text { successful at this course } \\
\text { Members of my family think that I } \\
\text { would be successful at this course }\end{array}$ & .922 \\
\hline $\begin{array}{l}\text { Usefulness related to own } \\
\text { children }\end{array}$ & 2 & $\begin{array}{l}\text { I would like to help my children in their } \\
\text { programming studies } \\
\text { After attending the course I will } \\
\text { understand my children who have } \\
\text { programming skills }\end{array}$ & .805 \\
\hline
\end{tabular}


The questionnaire ended with questions about background data, and self-evaluation of the probability of completing the $\mathrm{MOOC}$ in percentage terms in order to measure the intention to complete. Data about actual completion or non-completion of the MOOC was taken from the Moodle learning platform.

\section{Data Analysis}

SPSS version 25.0 was used for statistical data analysis. First, composite scores of individual items from the FIEM scale were calculated based on seven factors (Luik et al., 2019). The second step focused on building motivation clusters from composite score results of the FIEM scale. This was done by conducting a k-mean cluster analysis with the Euclidean distance and with a maximum of 10 iterations. Cluster analysis was used to group respondents based on motivational factors. As k-means cluster analysis is conducted with different numbers of clusters to find a solution that is the most meaningful in the research context (Jain, 2010), we tested the cluster models with three, four, and five clusters.

In the last phase, general linear models (multivariate and repeated measures) were used to describe differences between clusters. ANOVA (comparing intention to complete, which was measured in percentages) and chi-square test (comparing proportion of completers and non-completers) were used to answer the second research question.

\section{Results}

Based on the k-means cluster analysis, the respondents were divided into four groups according to their motivation at time of enrolling in the programming MOOC. The most meaningful results were obtained with four identified clusters, which showed the differences among the respondents (Table 2). 
Table 2

Descriptive Data of Motivation Clusters

\begin{tabular}{|c|c|c|c|c|c|c|c|c|}
\hline \multirow[t]{3}{*}{ Factor } & \multicolumn{2}{|c|}{$\begin{array}{c}\text { Cluster } 1 \\
\text { (Opportunity motivated) }\end{array}$} & \multicolumn{2}{|c|}{$\begin{array}{c}\text { Cluster } 2 \\
\text { (Over-motivated) }\end{array}$} & \multicolumn{2}{|c|}{$\begin{array}{c}\text { Cluster } 3 \\
\text { (Success motivated) }\end{array}$} & \multicolumn{2}{|c|}{$\begin{array}{c}\text { Cluster } 4 \\
\text { (Interest } \\
\text { motivated) }\end{array}$} \\
\hline & \multicolumn{2}{|c|}{$n=327$} & \multicolumn{2}{|c|}{$n=338$} & \multicolumn{2}{|c|}{$n=232$} & \multicolumn{2}{|c|}{$\mathrm{n}=284$} \\
\hline & $M$ & $S D$ & $M$ & $S D$ & $M$ & $S D$ & $M$ & $S D$ \\
\hline Social influence & 5.1 & 1.25 & $5 \cdot 7$ & 1.15 & 4.7 & 1.22 & 1.7 & 0.94 \\
\hline $\begin{array}{l}\text { Interest in and } \\
\text { expectations of } \\
\text { the course }\end{array}$ & 6.3 & 0.58 & 6.5 & 0.49 & 5.8 & 0.77 & 5.7 & 0.87 \\
\hline $\begin{array}{l}\text { Personal } \\
\text { suitability of } \\
\text { distance learning }\end{array}$ & 6.0 & 0.81 & 6.1 & 0.72 & 5.2 & 1.03 & 5.4 & 1.14 \\
\hline $\begin{array}{l}\text { Suitability for } \\
\text { family and work }\end{array}$ & 6.4 & 0.73 & 6.3 & 0.91 & 3.4 & 1.21 & 4.9 & 1.77 \\
\hline $\begin{array}{l}\text { Importance and } \\
\text { perceived ability }\end{array}$ & 5.1 & 0.91 & $5 \cdot 7$ & 0.83 & 4.7 & 0.95 & 4.0 & 1.05 \\
\hline $\begin{array}{l}\text { Usefulness related } \\
\text { to certification }\end{array}$ & 4.6 & 1.21 & $5 \cdot 4$ & 1.07 & 4.1 & 1.18 & 3.2 & 1.21 \\
\hline $\begin{array}{l}\text { Usefulness related } \\
\text { to own children }\end{array}$ & 1.8 & 1.08 & $5 \cdot 3$ & 1.15 & 2.2 & 1.39 & 2.2 & 1.54 \\
\hline
\end{tabular}

The first cluster comprised $\mathbf{2 7 . 7 \%}$ of all respondents. They gave the highest ratings to the motivational factor Suitability to family and work (significantly different from other factors in all cases $p<.05$ ). Their ratings were also high for the factors Interest in and expectations of the course and Personal suitability of distance learning (difference between each other and from other factors $p<.05$ ). The factors Suitability to family and work and Personal suitability of distance learning were also rated higher compared with other clusters, except cluster 2. It seems that, for these participants, taking a MOOC or another e-learning course can be the only possibility or a suitable opportunity to study an interesting topic. We named this cluster Opportunity motivated. 
The second cluster (28.6\% of respondents) was identified as Over-motivated. They rated almost all motivational factors higher than did members of other clusters $(p<.05)$. Only in the case of factors Suitability to family and work and Personal suitability of distance learning was there no statistically significant difference with cluster 1 . All the factor means were over 5 .

The smallest cluster (19.6\% of respondents) was cluster 3 . The highest-rated factors in this cluster included Interest in and expectations of the course, Personal suitability of distance learning (difference from other factors in both cases $p<.05$ ), Importance and perceived ability, and Social influence. The latter two were not significantly different from each other $(p>.05)$, but different from other factors (all $p<.05$ ). Because items such as I get more knowledge from this course, I need that knowledge in real life, I know that I do well in this topic, and members of my family think that I would be successful at this course belonged to these factors, we named this cluster Success motivated. Compared with clusters 1 and 2, the ratings in this cluster were all statistically lower (all $p<.05)$.

The fourth and last cluster included $24.0 \%$ of the participants. Compared with clusters 1 and 2, the respondents in this cluster gave lower ratings to motivational factors. The Social influence factor was the lowest rated among all clusters and was also the lowest rated in this cluster compared with other factors (all $p<.05$ ). The factors Importance and perceived ability and Usefulness related to certification were also rated lower than in other clusters (all $p<.05$ ). Learners in this cluster could be described as interested in the topic, as well as being people for whom this type of learning was suitable and significant others did not play a role in their enrollment in the MOOC. We identified this cluster as Interest motivated.

Comparing the clusters in terms of self-evaluated probability of completing the MOOC in percentages (Table 3), it was found with ANOVA that there was a statistically significant difference in evaluations between the clusters $(F=15.228, p<.001)$. Bonferroni Post Hoc tests indicated that Interest motivated learners evaluated the probability of completing the MOOC lower than did learners from the Opportunity motivated and Over-motivated clusters (in both cases $p<$.oo1). Over-motivated learners also evaluated the probability of completing the MOOC higher than did the Success motivated group $(p<.01)$. There were no other statistically significant differences between the clusters (all $p>$.05). 


\section{Table 3}

Self-Evaluated Probability of Completing the MOOC in Percentages by Clusters

\begin{tabular}{lcccc}
\hline Cluster & $\min$ & $\max$ & $M$ & $S D$ \\
\hline Opportunity motivated & 45 & 100 & 89.0 & 11.75 \\
& & & & \\
Over-motivated & 50 & 100 & 90.3 & 12.11 \\
Success motivated & 30 & 100 & 85.0 & 14.43 \\
Interest motivated & 7 & 100 & 83.4 & 16.86 \\
Total & 7 & 100 & 87.4 & 14.01 \\
\hline
\end{tabular}

Significant differences emerged when we compared the percentages of respondents in three clusters according to completion rate (Table 4). The percentage of completers was significantly higher than the percentage of non-completers in the Opportunity motivated, Success motivated, and Interest motivated clusters. There was no significant difference in the Over-motivated cluster.

The results also indicated that the percentage of learners in the Opportunity motivated and Interest motivated clusters who completed the MOOC was statistically higher than the respective proportion of completers in the Over-motivated cluster (accordingly, chi-square 6.829, $p=.001$ and chi-square 5.454, $p$ $=.020$ ). 


\section{Table 4}

Comparison of Percentages of Completers and Non-Completers in the Clusters

\begin{tabular}{|c|c|c|c|c|c|}
\hline \multirow[t]{2}{*}{ Cluster } & \multirow[t]{2}{*}{$n$} & \multirow[t]{2}{*}{ Completers } & \multirow[t]{2}{*}{$\begin{array}{l}\text { Non- } \\
\text { completers }\end{array}$} & \multicolumn{2}{|c|}{$\begin{array}{c}\text { Difference in percentages of } \\
\text { completers and non-completers }\end{array}$} \\
\hline & & & & chi-square & $p$ \\
\hline $\begin{array}{l}\text { Opportunity } \\
\text { motivated }\end{array}$ & 327 & $215(65.7 \%)$ & $112(34.3 \%)$ & 32.443 & $<.001$ \\
\hline Over-motivated & 338 & $178(52.7 \%)$ & $160(47 \cdot 3 \%)$ & .959 & .328 \\
\hline $\begin{array}{l}\text { Success } \\
\text { motivated }\end{array}$ & 232 & $131(56.5 \%)$ & $101(43.5 \%)$ & 3.879 & .049 \\
\hline $\begin{array}{l}\text { Interest } \\
\text { motivated }\end{array}$ & 284 & $176(62.0 \%)$ & $108(38.0 \%)$ & 16.282 & $<.001$ \\
\hline Total & 1181 & $700(59.3 \%)$ & $481(40.7 \%)$ & 40.610 & $<.001$ \\
\hline
\end{tabular}

The proportion of completers in the Opportunity motivated cluster was also significantly higher than in the Success motivated cluster (chi-square 4.959, $p=.026$ ). There was no statistically significant difference in completion rates between the Opportunity motivated and Interest motivated (chi-square .941, $p=.332$ ), Success motivated and Interest motivated (chi-square 1.607, $p=.205$ ), and Over-motivated and Success motivated (chi-square .801, $p=.371$ ) clusters.

\section{Discussion}

The aim of this study was to outline the main motivation clusters of participants in a computer programming MOOC, and to compare how these clusters differ in completion rate. The FIEM scale (Luik et al., 2019) based on expectancy-value theory (Eccles \& Wigfield, 2002) was used to form clusters of MOOC learners according to their motivation to enroll in the MOOC.

As an answer to the first research question-What kind of learner sub-groups (clusters) can be identified based on motivation? - we found four clusters of learners. Previous studies have identified three (Gallén \& Caro, 2017; Maya-Jariego et al., 2019) or five (Barak et al., 2016) clusters, but they used different motivational scales (Gallén \& Caro, 2017; Maya-Jariego et al., 2019) or were based only on e-mails and 
forum posts as data sources (Barak et al., 2016). It was interesting that the highest proportion of learners belonged to the cluster named Over-motivated, as they rated almost all motivational factors higher than did members of the other clusters. This finding aligned with the result of Maya-Jariego et al. (2019), who found that more than half of MOOC participants were highly motivated.

Opportunity motivated learners take advantage of e-learning courses, including MOOCs. They like distance learning and, due to family and work commitments, this kind of learning can be for them the only option for studying interesting topics. In terms of size, this cluster was just a little smaller than the Over-motivated cluster. The opportunity to learn about the topic was also mentioned as one of the four primary motives in a previous study (Milligan \& Littlejohn, 2017) and suitability of this kind of learning was among the three highest rated motivational factors in Luik et al. (2019).

Almost a quarter of learners belonged to the Interest motivated cluster-learners interested in the topic who find distance learning suitable for them and decided by themselves to enroll in the MOOC. It was interesting that only a quarter of the participants belonged to this cluster because interest has been reported as one of the highest motivational factors (Kizilcec \& Schneider, 2015; Luik et al., 2019; Milligan \& Littlejohn, 2017; White et al., 2015). These learners were not influenced by others; a similar cluster was found in a previous study (Maya-Jariego et al., 2019), where the self-referential cluster was also described as people who felt less pressured by the opinion of family and friends.

The smallest cluster, Success motivated, could be described as people oriented towards getting more benefit from the course. They and their significant others believe that they can be successful studying this topic. Barak et al. (2016) identified a similar cluster, named benefactors. Like our Success motivated cluster, they wanted to learn for their own benefit, but according to the previous study (Barak et al., 2016) they also wanted to contribute to society, which was not a trait identified in our study. A previous study (Chaw \& Tang, 2019) also observed that confidence in one's ability to perform well and valuing learning for its usefulness leads to increased tendency to complete MOOCs.

Second, we examined differences among the clusters according to the intention to complete the MOOC and according to completion rates. Interest motivated respondents evaluated their probability of completing the MOOC lower than did the Opportunity motivated and Over-motivated respondents. This could be related to the tendency of some learners to choose only parts of MOOC according to their interests (Kizilcec \& Schneider, 2015; Wang \& Baker, 2015; White et al., 2015). Therefore, it is possible that they simply intend to satisfy their curiosity and, as a result, they know that they are not very likely to complete the MOOC. Maya-Jariego et al. (2019) argued that the intention to initiate and complete a MOOC was highest in a highly motivated cluster, which was supported by our study. Over-motivated learners evaluated their probability of completing the MOOC higher than did Interest motivated and Success motivated respondents.

Unlike the findings of Breslow et al. (2013), our results indicated that motivation for enrollment is related to completion of the course. The comparison of completion rates indicated that the proportion of completers was higher than the proportion of non-completers in all clusters, except for the Over-motivated. The result that almost two-thirds of learners from the Opportunity motivated cluster completed the course indicated that this type of motivation seems to be the most beneficial for completing a MOOC. Learners who are 
comfortable with distance learning might be better equipped to cope with the difficulties of a MOOC, to keep motivated and, therefore, complete the MOOC (Luik et al., 2018).

More than $60 \%$ of the participants in the Interest motivated cluster completed the MOOC. Also, the results indicated that the intention to complete is not related to actual completion. While Interest motivated learners evaluated their probability of completing the $\mathrm{MOOC}$ almost the lowest, the completion rate in this cluster was higher than among Over-motivated learners and not significantly different from the other clusters. The results of previous studies about the relationships between interest and completion have been inconsistent. For example, Luik et al. (2018) found that completers rated interest-related motivational items higher than did non-completers, but the findings of Evans et al. (2016) indicated that MOOC learners motivated by curiosity tended to drop out. Interest in the course content leads to completion, but interest in MOOCs as a special type of learning did not (Wang \& Baker, 2015). Consequently, it seems that the interaction between interest and completion needs further study.

An interesting finding was that learners in the Over-motivated cluster, having reported the highest motivation, dropped out more than did Opportunity motivated and Interest motivated participants. MayaJariego et al. (2019) claimed, based on intention to complete, that motivation expressed before the course was a relevant predictor of varying dropout rates and learners with higher motivation at the beginning of the MOOC were more likely to complete. However, our results did not support this statement. Also, it seems that orientation to success is not particularly beneficial for completing a MOOC.

\section{Conclusion and Implications}

Our findings can be useful for MOOC instructors, as a better vision of participants' motivational profiles at the beginning of the MOOC might help to design better supports for different learners and result in lower dropout rates. Learners who are highly motivated at the beginning of a MOOC might get less attention because it is assumed that they do not need so much outside support. However, our results indicated that learners with high motivation in all areas tended to drop out. The reason might be that, compared with others, they had a less clear idea about why they needed this MOOC.

The other group of learners needing more attention includes those who believe that they can be successful in the subject area of the MOOC, partially because they are convinced by their family members and friends. However, merely believing in success does not help one complete a MOOC and such learners may be more prone to being distracted when difficulties arise.

The study has some limitations that must be taken into account. The number of participants was low compared with the number of participants commonly found in MOOCs, but the participation rate was still considerable. Also, this MOOC was about computer programming and with a higher completion rate than the average; the results may be not generalizable to other MOOCs. Furthermore, as is usual in studies on motivation, we used a self-reported scale.

In future studies, it would be interesting to extend our work and explore larger samples and MOOCs with different topics. Additionally, considering the globality of MOOCs, it would be relevant to analyze the 
motivation to learn and completion rates among culturally diverse learners. The relationships between motivation and completion need more attention in future investigations, because it is still not clear how interest influences completion. Also, the actual reasons for highly motivated participants dropping out are still vague and could, therefore, prove to be a very beneficial avenue of research. 


\section{References}

Anthony, G., \& Ord, K. (2008). Change-of-career secondary teachers: Motivations, expectations and intentions. Asia-Pacific Journal of Teacher Education, 36(4), 359-376.

https://doi.org/10.1080/13598660802395865

Barak, M., Watted, A., \& Haick, H. (2016). Motivation to learn in massive open online courses: Examining aspects of language and social engagement. Computers \& Education, 94, 49-60.

https://doi.org/10.1016/j.compedu.2015.11.010

Breslow, L. B., Pritchard, D. E., DeBoer, J., Stump, G. S., Ho, A. D., \& Seaton, D. T. (2013). Studying learning in the worldwide classroom: Research into edX's first MOOC. Research \& Practice in Assessment, 8, 13-25. http://www.rpajournal.com/studying-learning-in-the-worldwideclassroom-research-into-edxs-first-mooc/

Brookhart, S. M., \& Freeman, D. J. (1992). Characteristics of entering teacher candidates. Review of Educational Research, 62(1), 37-60. https://doi.org/10.2307/1170715

Brophy, J. E. (2013). Motivating students to learn. Routledge.

Chaw, L. Y., \& Tang, C. M. (2019). Driving high inclination to complete massive open online courses (MOOCs): Motivation and engagement factors for learners. The Electronic Journal of e-Learning, 17(2), 118-130. https://eric.ed.gov/?id=EJ1221333

Daza, V., Makriyannis, N., \& Rovira Riera, C. (2013). MOOC attack: Closing the gap between preuniversity and university mathematics. Open Learning: The Journal of Open, Distance and eLearning, 28(3), 227-238. https://doi.org/10.1080/02680513.2013.872558

Deci, E. L., Koestner, R., \& Ryan, R. M. (2001). Extrinsic rewards and intrinsic motivation in education: Reconsidered once again. Review of Educational Research, 71(1), 1-27. https://doi.org/10.3102/00346543071001001

Douglas, K. A, Merzdorf, H. E., Hicks, N. M., Sarfraz, M. I., \& Bermel, P. (2020). Challenges to assessing motivation in MOOC learners: An application of an argument-based approach. Computers \& Education, 150. https://doi.org/10.1016/j.compedu.2020.103829

Eccles, J. S., \& Wigfield, A. (2002). Motivational beliefs, values, and goals. Annual Review of Psychology, 53(1), 109-132. https://doi.org/10.1146/annurev.psych.53.100901.135153

Evans, B. J., Baker, R. B., \& Dee, T. S. (2016). Persistence patterns in massive open online courses (MOOCs). The Journal of Higher Education, 87(2), 206-242. https://doi.org/10.1080/00221546.2016.11777400

Feklistova, L., Lepp, M., \& Luik, P. (2019). Completers' engagement clusters in programming MOOC: The case of Estonia. In L. Gómez Chova, A. López Martínez, \& I. Candel Torres (Eds.), ICERI 2019 
Proceedings: 12th annual international conference of education, research and innovation (pp. 1119-1126). IATED.

Gallén, R. C., \& Caro, E. T. (2017). An exploratory analysis of why a person enrolls in a massive open online course within MOOCKnowledge data collection. IEEE Global Engineering Education Conference (pp. 1600-1605). https://doi.org/10.1109/EDUCON.2017.7943062

Green, J., Liem, G. D., Martin, A. J., Colmar, S., Marsh, H. W., \& McInerney, D. (2012). Academic motivation, self-concept, engagement, and performance in high school: Key processes from a longitudinal perspective. Journal of Adolescence, 35, 1111-1122. https://doi.org/10.1016/j.adolescence.2012.02.016

Grover, S., Franz, P., Schneider, E., \& Pea, R. (2013). The MOOC as distributed intelligence: Dimensions of a framework \& evaluation of MOOCs. 1oth International Conference on Computer Supported Collaborative Learning. https://www.researchgate.net/publication/275771115 The MOOC as Distributed Intelligence Dimensions of a Framework_Evaluation_of_MOOCs

Huitt, W. (2011). Motivation to learn: An overview. Educational Psychology Interactive. Valdosta State University. http://www.edpsycinteractive.org/topics/motivation/motivate.html

Jain, A. K. (2010). Data clustering: 50 years beyond K-means. Pattern Recognition Letters, 31(8), 651666. https://doi.org/10.1016/j.patrec.2009.09.011

Kahan, T., Soffer, T., \& Nachmias, R. (2017). Types of participant behavior in a massive open online course. International Review of Research in Open and Distributed Learning, 18(6), 1-18. https://doi.org/10.19173/irrodl.v18i6.3087

Kizilcec, R. F., Piech, C., \& Schneider, E. (2013). Deconstructing disengagement: Analyzing learner subpopulations in massive open online courses. In D. Suthers, K. Verbert, \& E. Duval (Eds.), Proceedings of the third international conference on learning analytics and knowledge (pp. 170179). https://doi.org/10.1145/2460296.2460330

Kizilcec, R. F., \& Schneider, E. (2015). Motivation as a lens to understand online learners: Toward datadriven design with the OLEI scale. ACM Transactions on Computer-Human Interactions, 22(2). https://doi.org/10.1145/2699735

Lepp, M., Luik, P., Palts, T., Papli, K., Suviste, R., Säde, M., \& Tõnisson, E. (2017). MOOC in programming: A success story. In L. Campbel \& R. Hartshorne (Eds.), Proceedings of the International Conference on e-Learning (ICEL; pp. 138-147). Academic Publishing International (API).

Luik, P., Lepp, M., Palts, T., Säde, M., Suviste, R., Tõnisson, E., \& Gaiduk, M. (2018). Completion of Programming MOOC or Dropping out: Are There any Differences in Motivation? In K. Ntalianis, A. Andreatos, and C. Sgouropoulou (Eds.), Proceedings of the 17th European Conference on e- 
Learning ECEL 2018 (pp. 329-337). Academic Conferences and Publishing International Limited Reading.

Luik, P., Suviste, R., Lepp, M., Palts, T., Tõnisson, E., Säde, M., \& Papli, K. (2019). What motivates enrolment in programming MOOCs? British Journal of Educational Technology, 5O(1), 153-165. https://doi.org/10.1111/bjet.12600

Macdonald, P., \& Ahern, T. C. (2015). Exploring the instructional value and worth of a MOOC. Journal of Educational Computing Research, 52(4), 496-513. https://doi.org/10.1177/0735633115571927

Maya-Jariego, I., Holgado, D., González-Tinoco, E., Castaño-Muñoz, J., \& Punie, Y. (2019). Typology of motivation and learning intentions of users in MOOCs: The MOOCKNOWLEDGE study.

Educational Technology Research and Development, 68, 203-224. https://doi.org/10.1007/s11423-019-09682-3

Milligan, C. \& Littlejohn, A. (2017). Why study on a MOOC? The motives of students and professionals. The International Review of Research in Open and Distributed Learning, 18(2). https://doi.org/10.19173/irrodl.v18i2.3033

Orhan Özen, S. (2017). The effect of motivation on student achievement. In E. Karadag (Ed.), The factors effecting student achievement (pp. 35-56). https://doi.org/10.1007/978-3-319-56083-0 3

Pintrich, P. R. (2003). A motivational science perspective on the role of student motivation in learning and teaching contexts. Journal of Educational Psychology, 95, 667-686.

https://doi.org/10.1037/0022-0663.95.4.667

Reparaz, C., Aznárez-Sanado, M., \& Mendoza, G. (2020). Self-regulation of learning and MOOC retention. Computers in Human Behavior, 111. https://doi.org/10.1016/j.chb.2020.106423

Tomšik, R. (2016). Choosing teaching as a career: Importance of the type of motivation in career choices. TEM Journal, 5(3), 396-400. https://doi.org/10.18421/TEM53-21

Tseng, S., Tsao, Y., Yu, L., Chan, C., \& Lai, K. R. (2016). Who will pass? Analyzing learner behaviors in MOOCs. Research and Practice in Technology Enhanced Learning, 11(8), 1-11.

https://doi.org/10.1186/s41039-016-0033-5

Wang, Y., \& Baker, R. (2015). Content or platform: Why do students complete MOOCs? Journal Of Online Learning \& Teaching, 11(1), 17-30. https://jolt.merlot.org/vol11no1/Wang 0315.pdf

Watted, A., \& Barak, M. (2018). Motivating factors of MOOC completers: Comparing between universityaffiliated students and general participants. The Internet and Higher Education, 37, 11-20. https://doi.org/10.1016/j.iheduc.2017.12.001

White, S., Davis, H., Dickens, K., Leon, M., \& Sanchez-Vera, M. M. (2015). MOOCs: What motivates the producers and participants? In S. Zvacek, M. Restivo, J. Uhomoibhi, \& M. Helfert (Eds.), 
Computer supported education: CSEDU 2014 (pp. 99-114). https://doi.org/10.1007/978-3-31925768-6_7

Wigfield, A., \& Eccles, J. S. (2000). Expectancy-value theory of achievement motivation. Contemporary Educational Psychology, 25(1), 68-81. https://doi.org/10.1006/ceps.1999.1015

Wigfield, A., Eccles, J. S., \& Möller, J. (2020). How dimensional comparisons help to understand linkages between expectancies, values, performance, and choice. Educational Psychology Review, 32(3), 657-68o. https://doi.org/10.1007/s10648-020-09524-2

Zheng, S., Rosson, M. B., Shih, P. C., \& Carroll, J. M. (2015). Understanding student motivation, behaviors and perceptions in MOOCs. Proceedings of the 18th ACM conference on computer supported cooperative work \& social computing (pp. 1882-1895).

https://doi.org/10.1145/2675133.2675217

\section{Athabasca}

University

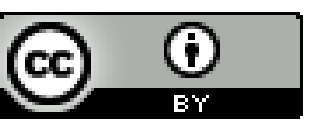

